\title{
A Subacute Thyroiditis Case After SARS-CoV-2 Infection: A Case Report and Current Literature Review
}

\author{
๑ Muge Ayhan, ๑ Rahmet Guner* \\ Ankara City Hospital, Clinic of Infectious Diseases and Clinical Microbiology, Ankara, Turkey \\ ${ }^{*}$ Ankara Yıldırım Beyazıt University, Ankara City Hospital, Clinic of Infectious Diseases and Clinical Microbiology, Ankara, Turkey
}

\section{Abstract}

\begin{abstract}
Subacute thyroiditis (SAT), is a self-limiting inflammatory disorder which is linked to a viral infection. A few cases of SAT were reported after Severe Acute Respiratory syndrome Coronavirus-2 (SARS-CoV-2) infection. We here reported a case of SAT that occurred two weeks after SARS-CoV-2 infection. A thirty-nine-year-old male with no comorbid diseases applied to our outpatient clinic with the complaints of sore throat, fatigue and subfebrile fever. He had a contact history of his wife who has a positive SARS-CoV-2 reverse transcription polymerase chain reaction (RT-PCR) test. The nasopharyngeal swab was performed and his SARS-CoV-2 RT-PCR test was confirmed positive. He recovered from all symptoms in one week. On the second week of the first diagnosis, he developed neck pain, fatigue, muscle pains, palpitation and tremors. Because his thyroid palpation was painful and he was more symptomatic thyroid function tests were performed. Thyrotropin was suppressed $(0.01 \mathrm{mIU} / \mathrm{L})$, free triiodothyronine and free thyroxine levels were high as $11 \mathrm{ng} / \mathrm{L}$ and $3.72 \mathrm{ng} / \mathrm{dL}$, respectively. His cervical ultrasound also revealed SAT. He was treated with prednisolone, ibuprofen and propranolol. Within one week, there was a progressive resolution of signs and symptoms. After the third week, his laboratory results returned to normal ranges.
\end{abstract}

Keywords: Subacute thyroiditis, viral infection, COVID-19, endocrinology, antiviral treatment

\section{Introduction}

Subacute thyroiditis (SAT), which is also called de Quervain's thyroiditis is a self-limiting inflammatory disorder of the thyroid gland and a relatively rare cause of thyrotoxicosis generally linked to viral infection (1). It is the most common cause of anterior cervical pain (2). It is characterized by acute onset of neck pain, general symptoms and thyroid dysfunction mostly preceded by an upper respiratory infection which are caused by several viruses $(1,3,4)$. A few cases of SAT after Severe Acute Respiratory syndrome Coronavirus-2 (SARS-CoV-2) infection was reported in the literature $(1,5-8)$. We here report a case of SAT which occurred two weeks after SARS-COV-2 infection.

\section{Case Report}

A thirty-nine-year-old male with no medical history of concomitant disease applied to infectious diseases outpatient clinic with complaints of sore throat, fatigue and subfebrile fever. Chest X-ray was normal. Complete blood count, blood biochemistry and inflammatory markers were within normal ranges. He had a contact history with her wife who had a positive nasopharyngeal swab test for SARS-COV-2 RNA. His SARS-CoV-2 reverse transcription polymerase chain reaction test was confirmed positive. Because he was symptomatic, favipiravir (with a loading dose of $800 \mathrm{mg}$ bid, maintenance dose of $300 \mathrm{mg}$ bid) was initialized according to national interim guideline (9). He recovered from all symptoms in one week. On the second week on the $28^{\text {th }}$ of December, 2020 he developed pain, tenderness in the anterior cervical area, fatigue, muscle pains, palpitation and tremors. He was afebrile. On the physical examination palpation of the thyroid gland was painful and thyroid gland was enlarged, other systems were normal. Because he was more symptomatic and the thyroid gland was enlarged, complete blood count, blood chemistry, sedimentation, C-reactive protein (CRP) and thyroid function tests were performed. Serum markers of acute inflammation were positive (erythrocyte sedimentation rate, $79 \mathrm{~mm} / \mathrm{h}$; CRP, $74.9 \mathrm{mg} / \mathrm{L}$ ), while

Address for Correspondence: Muge Ayhan, Ankara City Hospital, Clinic of Infectious Diseases and Clinical Microbiology, Ankara, Turkey 
white blood cell $\left(10.6 \times 10^{9} / \mathrm{L}\right)$ and lymphocyte count (1.2 $\times 10^{9} / \mathrm{L}$ ) were within the normal ranges. Hepatic and renal function tests were within normal ranges. Thyrotropin (TSH) was suppressed $(0.01 \mathrm{mIU} / \mathrm{L})$, free triiodothyronine (fT3) and free thyroxine (fT4) levels were high as 11 $\mathrm{ng} / \mathrm{L}$ and $3.72 \mathrm{ng} / \mathrm{dL}$, respectively. TSH-receptor and antithyroglobulin antibodies were negative. His Coronavirus disease-2019 (COVID-19) lgM+lgG serology was positive. Viral hepatitis serology and anti-HIV tests were negative. Electrocardiogram demonstrated sinus tachycardia. His thyroid ultrasound was consistent with subacute thyroiditis. Prednisolone $16 \mathrm{mg} /$ day, ibuprofen with a dose of $1200 \mathrm{mg} /$ day and propranolol with a dose of $20 \mathrm{mg}$ tid was initialized. Under this therapy, there was a progressive resolution of signs and symptoms. Within one week inflammatory markers became normal (Table 1). Prednisolone dosage reduced consecutively. In the third week, fT3 and fT4 levels started to reduce. In the fifth week, all thyroid tests were normalized and all of the symptoms were resolved and the treatment was stopped. Since this article is a case report, it does not contain any studies with animal or human participants performed by any of the authors. Informed consent has been obtained from the patient for publication of the case report.

\section{Discussion}

SAT was first defined in 1904 by DeQuervain. Viral infections are frequently addressed as a major cause of SAT and autoimmune thyroid diseases (3). Because most of the cases have been followed by upper respiratory tract infections or sore throats, viral infection was suggested as the main cause of SAT $(3,4)$. It was associated with outbreaks of mumps, and the mumps virus has been cultured from the thyroid glands of included cases (10). The onset of the reported cases is often observed in summer (usually between June and September) and this seasonal distribution is similar to that of established some viral infections due to some Enteroviruses (such as Echovirus, Coxsackievirus $A$ and $B$ ). It suggests that enteroviral infections might be responsible for most of the cases (11). Several viruses such as influenza, adenovirus, or less commonly Epstein-Barr and cytomegalovirus were also accused (1). SAT is often observed in women. It usually starts with sudden neck pain and is characterized by thyrotoxicosis in the beginning. Clinical symptoms have typical characteristics of viral infections including a prodromal episode with myalgia, fatigue and muscle pain (3). The thyroid gland is painful, tender and enlarged on palpation (6). Diagnosis of SAT is mainly based on clinical features, but also laboratory tests and imaging are also used (6).

The COVID-19 pandemic has started in late 2019 and rapidly has spread worldwide, with over 100 million people got infected, more than 2 million people have died because of this disease (12). COVID-19 can cause many chronic conditions in many organ systems. Thyroid dysfunction was reported in several cases $(13,14)$. Also, a a few SAT cases were reported after SARS-CoV-2 infection $(8,14)$. We here reported a case of SAT that occurred in a patient after SARS-CoV-2 infection. Although it is frequently observed in women in the literature, our patient was a thirty-nine-year-old male. The first symptoms of our case were neck pain, fatigue, muscle pain and the signs of thyrotoxicosis were observed, such as palpitation and tremors which were consistent with the previous literature $(3,4,8)$. The natural clinical course of SAT includes an initial thyrotoxic phase followed by a hypothyroid phase with recovery to a euthyroid state (15). Our case was in a hyperthyroid state in admission, after three weeks his thyroid hormone levels started to reduce and on the fifth week he became euthyroid. The treatment choices include corticosteroids, non-steroid antiinflammatory drugs and beta-blockers if needed (15-17). Our patient had received prednisolone, ibuprofen and propranolol and symptoms started to resolve and in one week inflammatory markers became normal.

\begin{tabular}{|l|l|l|l|l|l|}
\hline \multicolumn{1}{|l|}{ Table 1. Laboratory findings of patient } \\
\hline & Reference ranges & $\mathbf{2 8 . 1 2 . 2 0 2 0}$ & $\mathbf{0 5 . 0 1 . 2 0 2 1}$ & $\mathbf{1 8 . 0 1 . 2 0 2 1}$ & $\mathbf{0 5 . 0 2 . 2 0 2 1}$ \\
\hline WBC $\left(\times 10^{9} / \mathrm{L}\right)$ & $3.9-10.2$ & 10.6 & 9.4 & 9.7 & 8.58 \\
\hline Lymphocyte count $\left(\times 10^{9} / \mathrm{L}\right)$ & $1.1-4.5$ & 1.2 & 1.6 & 3 & 2.97 \\
\hline CRP $(\mathrm{mg} / \mathrm{L})$ & $0-5$ & 74.9 & 5.35 & 0.5 & 0.5 \\
\hline Erytrocyte sedimentation rate $(\mathrm{mm} / \mathrm{h})$ & $0-20$ & 79 & 73 & 3 & - \\
\hline Free T3 $(\mathrm{ng} / \mathrm{L})$ & $2.3-4.2$ & 11 & - & 3.32 & 2.75 \\
\hline Free T4 $(\mathrm{ng} / \mathrm{dl})$ & $0.89-1.76$ & 3.72 & - & 2.12 & 0.98 \\
\hline TSH $(\mathrm{mIU} / \mathrm{L})$ & $0.55-4.78$ & 0.01 & - & 0 & 2.19 \\
\hline Anti TG ( IU/mL) & $<1.3$ & 1 & - & - & 1 \\
\hline COVID-19 Ig M+lgG (index) & $0-0.99$ & $>10.00$ & - & - \\
\hline WBC: White blood cell, CRP: C-reactive protein, TSH: Thyrotropin, COVID-19: Coronavirus disease-2019 & & - \\
\hline
\end{tabular}


The pathogenesis and etiology of SAT remain unclear. But the most common thought is that, this disease is due to a viral etiology or a post-viral inflammatory reaction which is observed in individuals with a genetic predisposition $(6,18)$.

\section{Conclusion}

To date, a few cases of SAT have been reported during or after SARS-CoV-2 infection and we here reported a case of SAT which is probably associated with SARS-CoV-2 infection. Physicians should keep in mind that unusual clinical manifestations may be observed because of SARSCoV-2 infection and they can occur during or after the infection.

\section{Authorship Contributions}

Concept: M.A., Design: M.A., R.G., Data Collection or Processing: M.A., Analysis or Interpretation: M.A., R.G., Literature Search: M.A., R.G., Writing: M.A.

Conflict of Interest: No conflict of interest was declared by the authors.

Financial Disclosure: The authors declared that this study received no financial support.

\section{References}

1. Ruggeri RM, Campennì A, Siracusa M, Frazzetto G, Gullo D. Subacute thyroiditis in a patient infected with SARS-COV-2: an endocrine complication linked to the COVID-19 pandemic. Hormones (Athens) 2021;20:219-21.

2. Zhao N, Wang S, Cui XJ, et al. Two-Years Prospective FollowUp Study of Subacute Thyroiditis. Front Endocrinol (Lausanne) 2020;11:47.

3. Desailloud R, Hober D. Viruses and thyroiditis: an update. Virol J 2009;6:5.

4. Singer PA. Thyroiditis. Acute, subacute, and chronic. Med Clin North Am 1991;75:61-77.

5. Asfuroglu Kalkan E, Ates I. A case of subacute thyroiditis associated with Covid-19 infection. J Endocrinol Invest 2020;43:1173-4.

6. Brancatella A, Ricci $D$, Viola $N$, Sgrò $D$, Santini $F$, Latrofa F. Subacute Thyroiditis After Sars-COV-2 Infection. J Clin Endocrinol Metab 2020;105:276.
7. Mattar SAM, Koh SJQ, Rama Chandran S, Cherng BPZ. Subacute thyroiditis associated with COVID-19. BMJ Case Rep 2020;13:237336.

8. Erişkin Hasta Tedavisi. Bilimsel Danışma Kurulu Çalışması COVID-19. 2020;1-22. Available from: https://covid19.saglik. gov.tr/Eklenti/39061/0/covid-19rehberieriskinhastatedavisip df.pdf

9. EYLAN E, ZMUCKY R, SHEBA C. Mumps virus and subacute thyroiditis; evidence of a causal association. Lancet 1957;272:1062-3.

10. Martino E, Buratti L, Bartalena L, et al. High prevalence of subacute thyroiditis during summer season in Italy. J Endocrinol Invest 1987;10:321-3.

11. COVID-19 Coronavirus Pandemic [cited 2021 February 6]. Available from: https://www.worldometers.info/coronavirus/

12. Lui DTW, Lee CH, Chow WS, et al. Thyroid Dysfunction in Relation to Immune Profile, Disease Status, and Outcome in 191 Patients with COVID-19. J Clin Endocrinol Metab 2021; 106:926-35.

13. Harris A, Al Mushref M. Graves' Thyrotoxicosis Following SARS-CoV-2 Infection. AACE Clin Case Rep 2021; 7: 14-6.

14. Chakraborty U, Ghosh S, Chandra A, Ray AK. Subacute thyroiditis as a presenting manifestation of COVID-19: a report of an exceedingly rare clinical entity. BMJ Case Rep 2020;13:239953.

15. Alfadda AA, Sallam RM, Elawad GE, Aldhukair H, Alyahya MM. Subacute thyroiditis: clinical presentation and long term outcome. Int J Endocrinol 2014;2014:794943.

16. Subakut Granülomatöz Tiroidit (De Quervain Tiroiditi). In: Tiroid hastaliklari tanı ve tedavi kılavuzu. 5th ed. AnkaraTurkey: Türkiye Klinikleri; 2019. p. 90-6.

17. Duan L, Feng $X$, Zhang $R$, et al. Short-Term Versus 6-Week Prednisone In The Treatment of Subacute Thyroiditis: A Randomized Controlled Trial. Endocr Pract 2020;26:900-8.

18. Ohsako N, Tamai H, Sudo T, et al. Clinical characteristics of subacute thyroiditis classified according to human leukocyte antigen typing. J Clin Endocrinol Metab 1995;80:3653-6. 